\title{
Long-term Dwarfing Effects of Corticosteroid Treatment for Childhood Nephrosis
}

\author{
C. N. LAM and GAVIN C. ARNEIL \\ From the University Department of Child Health, Royal Hospital for Sick Children, Glasgow C.3
}

Children with the idiopathic nephrotic syndrome have been treated with intensive steroid therapy at various centres since prednisolone became available in 1955 . Five years after onset, $65-70 \%$ of such children are free from significant proteinuria, and the death rate has been reduced to $10-15 \%$ by such therapy (Arneil and Lam, 1966; Cornfeld and Schwartz, 1966). Serious untoward effects, such as those from cortisone recorded by Good, Vernier, and Smith (1957), were uncommon with prednisolone. An important side-effect of prolonged steroid therapy is inhibition of growth (Blodgett et al., 1956; Fleisher, McCrory, and Rapoport, 1960; Falliers et al., 1963). The purpose of this study is to review the growth pattern of a number of nephrotic children who have been followed up for 5 to 10 years after intensive steroid therapy.

\section{Materials and Methods}

Forty-five children were admitted to hospital with the idiopathic nephrotic syndrome in the years 19551960 inclusive: 5 of these children died, one recovered without steroid therapy, and one was treated with ACTH: 38 children remain who received intensive corticosteroid therapy as described previously (Arneil 1956; Arneil and Lam, 1966). The standing height of 33 of these 38 children was recorded before steroid therapy, at the end of steroid therapy, and at intervals thereafter until the end of the follow-up. The standard chart of heights used was that of Tanner and Whitehouse (1959).

\section{Results}

Distribution of heights before and at the end of steroid treatment and at the end of the follow-up for these 33 children is plotted in Fig. 1. Before treatment the height distribution of this group of children was skewed towards the lower centiles. This is likely to be due to the small number of children involved rather than to prolonged renal disease, since these children presented with such gross oedema that their admission to hospital was

Received March 7, 1968. not long delayed. When the values obtained at the end of prednisolone therapy are studied, a further shift of the height distribution to the lower centiles is seen. At the end of the follow-up period (5 to 10 years after cessation of steroids) the values indicate a shift back toward the normal height range. The height distribution at the 'end of steroid therapy' shown in Fig. 1 was recorded at the end of all steroid therapy. Thus, some children who had received several short courses of steroid because of relapses were given the opportunity to 'catch up' in

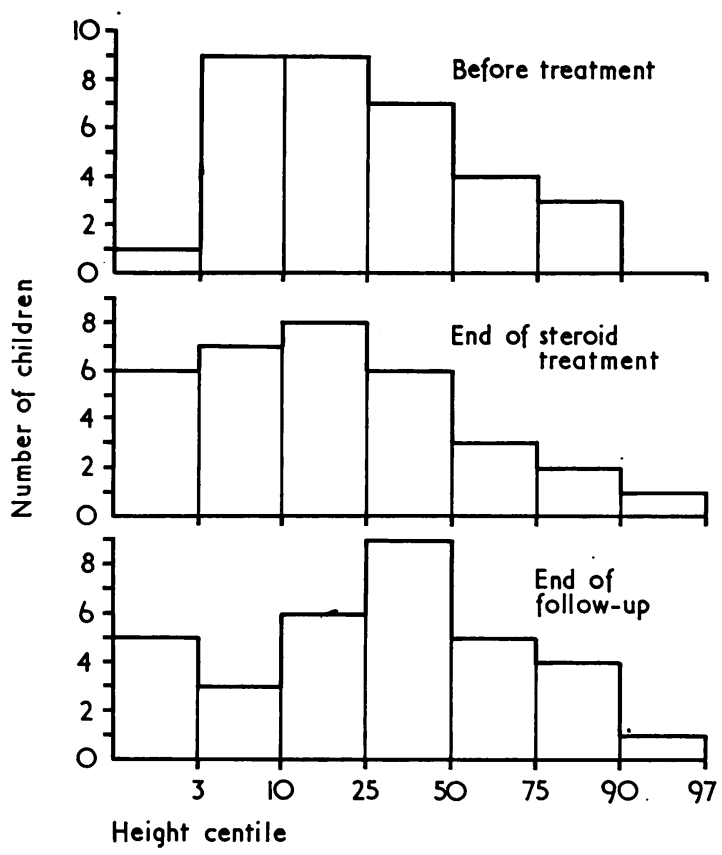

FIG. 1.-The distribution of height channels of 33 nephrotic children before, and at the end of steroid treatment, and at the end of follow-up.

Of the 5 children whose heights were under the third centile at the end of follow-up, 3 were frequent relapsers and 2 were under the 10th centile before steroid treatment. 
TABLE I

Change of Growth Channels at End of Steroid Treatment (33 Cases)

\begin{tabular}{|c|c|c|c|c|c|c|c|}
\hline \multirow{2}{*}{$\begin{array}{c}\text { Height } \\
\text { Channel }\end{array}$} & \multicolumn{6}{|c|}{ Total Duration of Steroid Treatment } & \multirow[b]{2}{*}{ Total } \\
\hline & $\begin{array}{l}\text { Up to } 3 \\
\text { months }\end{array}$ & $\begin{array}{l}3 \text { to } 6 \\
\text { months }\end{array}$ & $\begin{array}{l}6 \text { to } 12 \\
\text { months }\end{array}$ & $\begin{array}{l}12 \text { to } 18 \\
\text { months }\end{array}$ & $\begin{array}{l}18 \text { to } 24 \\
\text { months }\end{array}$ & $\begin{array}{l}\text { More than } 24 \\
\text { months }\end{array}$ & \\
\hline $\begin{array}{l}\text { Degraded } \\
\text { Stationary } \\
\text { Improved }\end{array}$ & $\begin{array}{l}0 \\
7 \\
1\end{array}$ & $\begin{array}{l}3 \\
5 \\
0\end{array}$ & $\begin{array}{l}2 \\
1 \\
1\end{array}$ & $\begin{array}{l}1 \\
2 \\
0\end{array}$ & $\begin{array}{l}0 \\
0 \\
0\end{array}$ & $\begin{array}{l}8 \\
0 \\
2\end{array}$ & $\begin{array}{r}14 \\
15 \\
4\end{array}$ \\
\hline
\end{tabular}

height between relapses (Fig. 2). Had such opportunity to 'catch up' in height not been given, the distribution of heights at the end of steroid therapy might have been further skewed towards the lower centiles. Two children are still on steroid treatment and thus have had no opportunity to grow after steroid therapy stopped, but are included in Fig. 1.

Table I relates duration of steroid therapy with changes in growth channel at the end of treatment. The height channel of nephrotic children may remain unaffected even after steroid therapy lasting up to a total of 18 months. Of the 14 children who were degraded in height growth channel, 8 subsequently improved in height growth after discontinuation of steroid therapy. Of these, 2 were still degraded by one height channel from their original. The results for up to six months therapy (a minimum of $1 \cdot 3 \mathrm{~g}$. prednisolone in the first 40 days of treatment) are particularly encouraging (Table II). Every one of these 16 children, of whom 3 were degraded in growth channel during treatment, returned to or remained in their original growth channel at long-term followup. Of the 7 children treated for 6-18 months, only 2 were degraded one growth channel from their original.

Two girls showed a remarkable growth pattern

TABLE II

Trends of Height Growth After Steroid Treatment (31 Cases ${ }^{\star}$ )

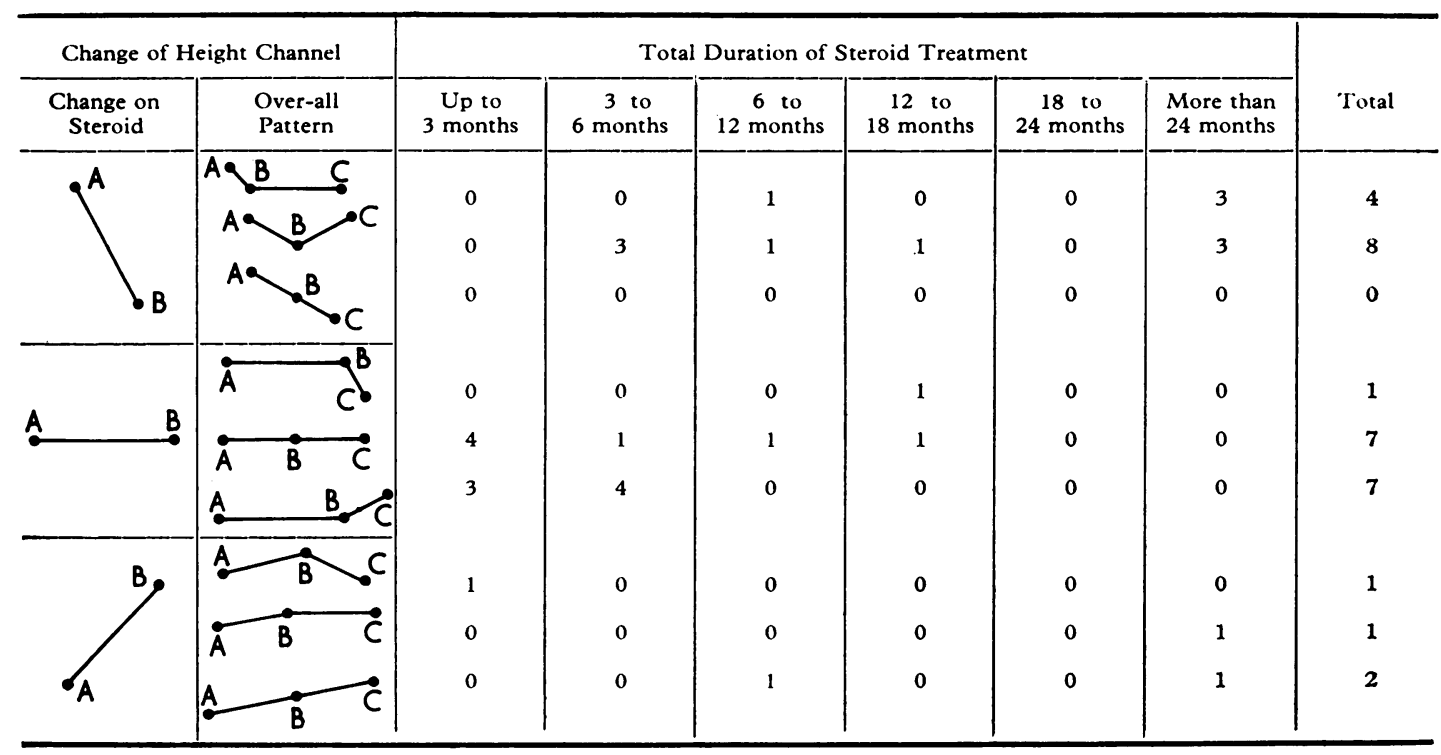

* Two children are still receiving steroid at present, and they are therefore not included in this table.

A-initial growth channel

B-growth channel at the end of steroid therapy

C-growth channel 5-10 years later 


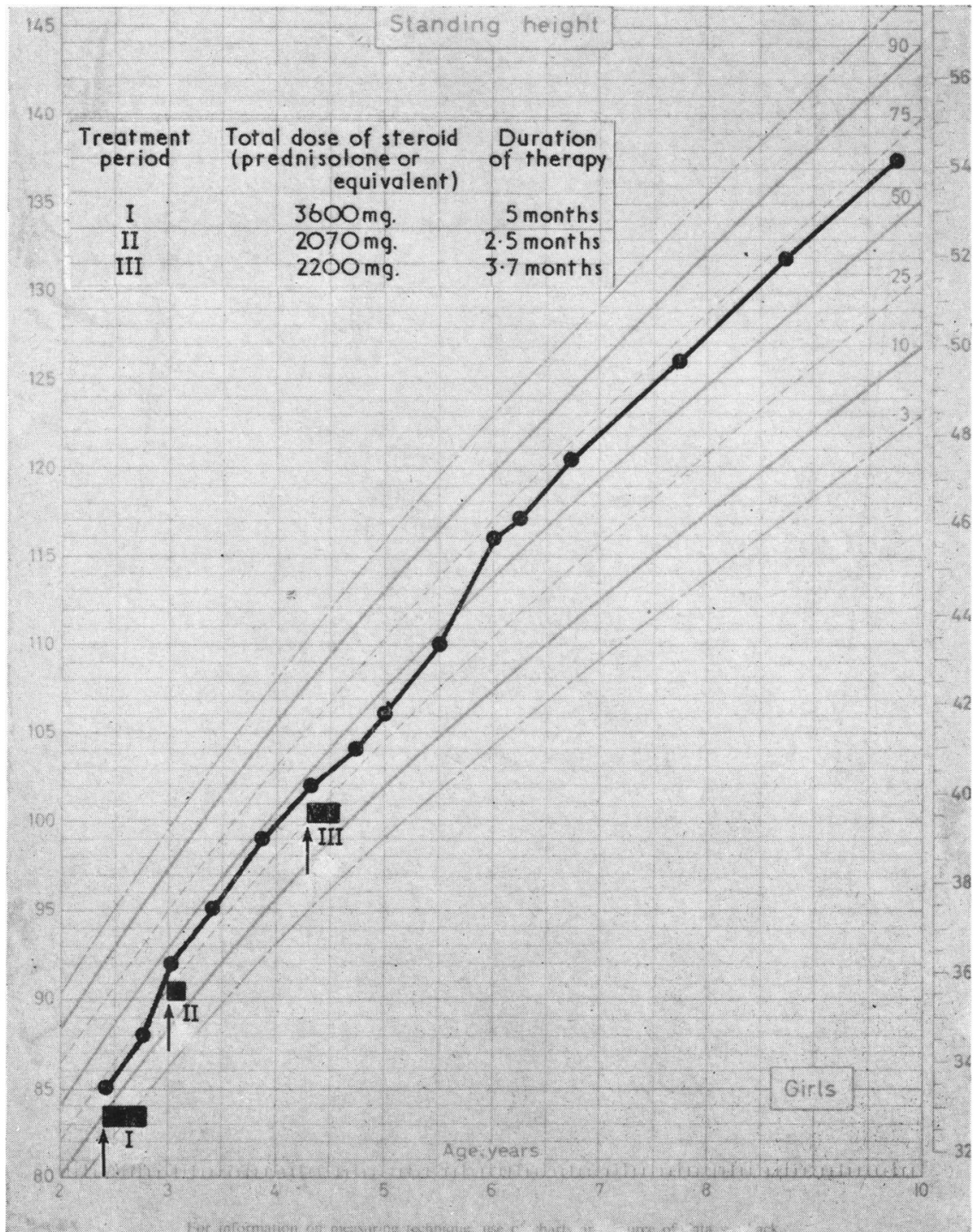

FIG. 2.-This girl who has had 3 episodes of nephrosis improved her growth channel between and after steroid treatments.

despite intensive steroid treatment. The first received several courses of continuous steroid therapy totalling 3 years 4 months, but still improved in height channel after steroid treatment (see Fig. 3). For approximately half of the duration of her steroid therapy this girl had received $2.5 \mathrm{mg}$. prednisolone per day. The second girl continued to improve in height despite receiving a total of 3 years steroid therapy spread over a $5 \frac{1}{2}$ year period. During one period of 14 months she received 50-100 mg. cortisone acetate weekly.

\section{Discussion}

In assessing the linear growth of nephrotic children treated with steroid, it should be recalled that $40 \%$ of such children have one episode only, and require one short course of intensive steroid therapy (Arneil and Lam, 1967). 12 children who received steroid therapy for less than six months remained in the same height channel at the end of steroid therapy. 7 of these subsequently improved their height growth channel. Steroid may have 


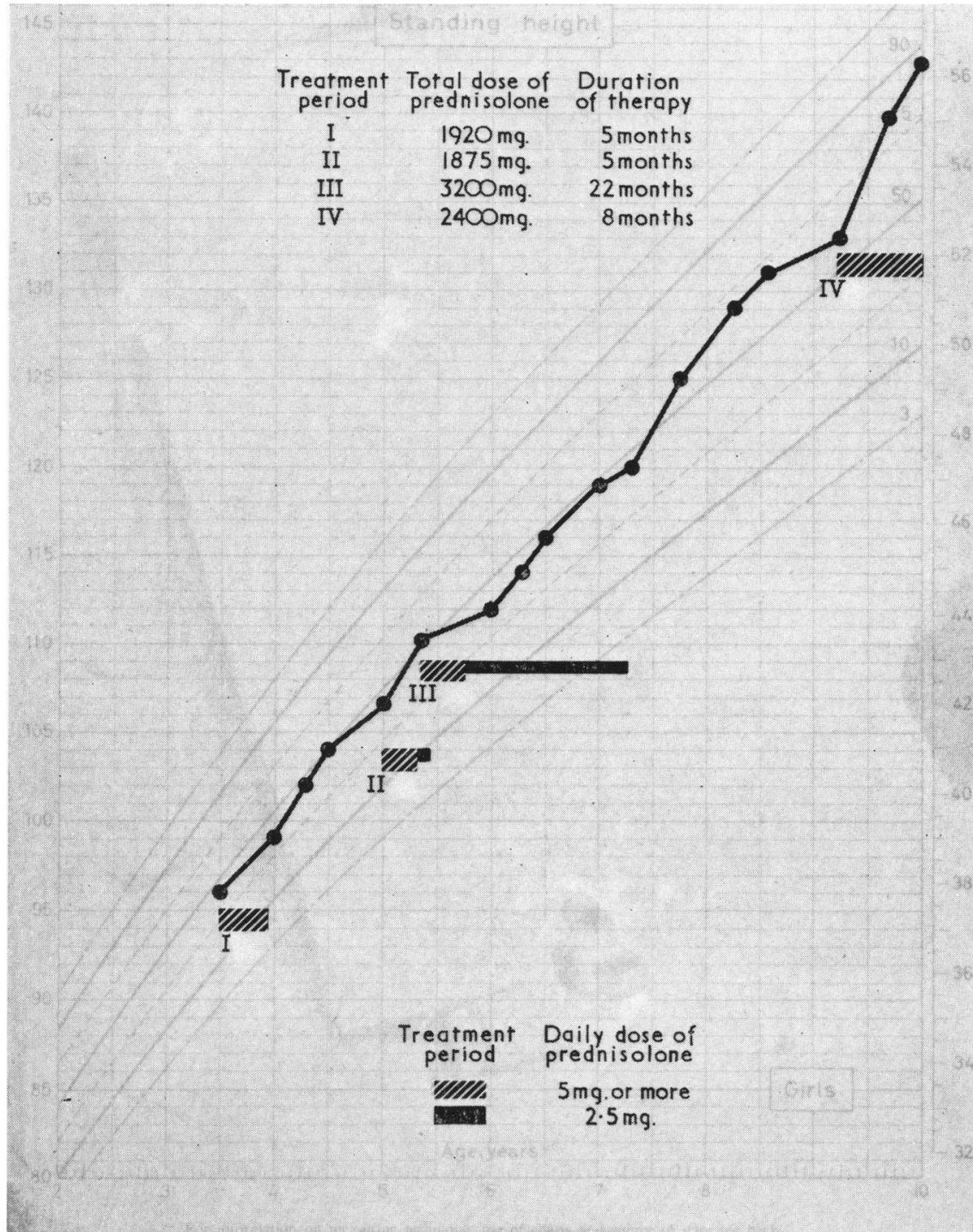

FIG. 3.-This girl who received prolonged steroid treatment continues to improve her height between treatment, and at one stage even during intensive treatment. This is exceptional.

delayed the growth of 14 children during the treatment period, but when steroid therapy was discontinued, 8 who had been degraded in height growth channel caught up in linear growth. This finding confirms the work of Fleisher et al. (1960) and Blodgett et al. (1956).

Growth suppression still remains an important problem in the management of frequent relapsers and steroid-dependent patients who tend to receive repeated long courses of steroid therapy (see Fig. 4). Various regimens have been suggested in the hope of eliminating the side-effects of longterm steroid treatment. Among these are intermittent steroid therapy (Lange, Slobody, and Strang, 1955) and alternate day steroid therapy (Soyka and Saxena, 1965; Soyka, 1967). Recently 'immunosuppressive' drugs have been used in the treatment of steroid-resistant nephrotics and of steroid-responsive nephrotics who relapse frequently (West, Hong, and Holland 1966; White, 


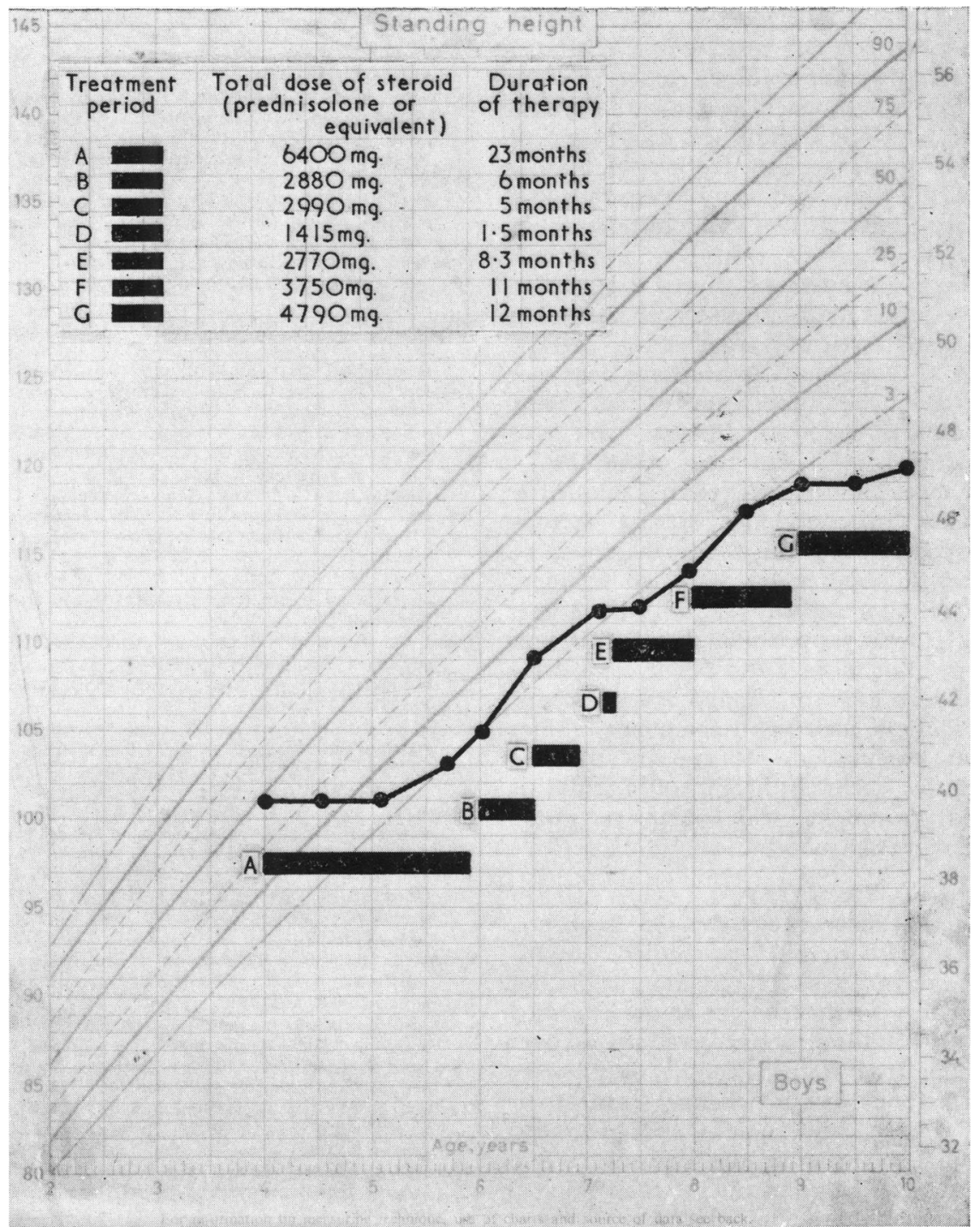

FIG. 4.-This boy who is a steroid-dependent nephrotic has been receiving steroid treatment practically continuously. Growth suppression is obvious.

Cameron, and Trounce 1966; Grupe and Heymann, 1966; Etteldorf et al., 1967; Michael et al., 1967). Good results have been claimed by a number of workers, but remain to be substantiated by large-scale trials. Friedman and Strang (1966) have suggested that intramuscular ACTH therapy avoids the growth suppressive effects of corticosteroid in asthmatic and nephrotic children: their interesting results await confirmation, though any prolonged intramuscular treatment to a child, unless essential, is undesirable.
Central and peripheral anatagonism between steroid and growth hormone has been suggested by various workers (Hartog, Gaafar, and Fraser, 1964; Frantz and Rabkin, 1964; Soyka and Crawford, 1964). Ward, Hartog, and Ansell (1966) found that human growth hormone (HGH) administration could partially overcome the growth suppressive effects in rheumatoid children treated with $3 \mathrm{mg}$. prednisolone daily, but not in children receiving $6 \mathrm{mg}$. prednisolone per day. Hartog et al. (1964) found HGH secretion subnormal after 
insulin-induced hypoglycaemia in patients receiving long-term steroid treatment. Friedman and Strang (1966) postulate the existence of some unknown adrenal hormone which may be a growthpromoting factor. The diminished production of such substances might account for growth retardation produced by prolonged steroid therapy and a return to normal growth rate when corticotrophin is given.

Whether the pathogenesis of growth suppression turns out to be prepituitary, pituitary, or adrenal in origin, it is apparent that prolonged steroid therapy may give rise to dwarfism. It has long been our practice to stress the importance of not overtreating the $40 \%$ of nephrotic children who have one episode only (Arneil and Lam, 1966, 1967). However, for those children who relapse frequently some alternative to continuous steroid therapy prolonged beyond a total of 6 months must be sought if growth suppression is to be avoided. Intermittent or alternate-day steroid therapy is probably less growth suppressing than continuous steroid therapy, but is far from being completely harmless to linear growth. 'Immunosuppressants' and ACTH therapy therefore remain possibilities worth further exploration. It appears that no anxiety over the eventual height of a child is necessary for treatment with intensive corticosteroid lasting up to 6 months.

\section{Summary}

The long-term linear growth of 33 nephrotic children treated with steroid was studied. Intensive steroid therapy up to a total of 6 months did not seem to affect the eventual height at the end of 5 to 10 years. Of 7 children who received steroid over a period totalling from 6 to 18 months, only 2 were finally degraded one height channel from their original. Of the 14 children who were degraded in their height channels at the end of steroid treatment, 6 subsequently returned to their original height channel and 2 showed improvement.

Growth suppression remains an important problem in the small group of nephrotic children who are steroid dependent or frequent relapsers.

We thank Dr. K. S. Tsien, U.N.I.C.E.F. Fellow, for help in analysing the data.

\section{REFERENCES}

Arneil, G. C. (1956). Treatment of nephrosis with prednisolone. Lancet, 1, 409.

—, and Lam, C. N. (1966). Long-term assessment of steroid therapy in childhood nephrosis. ibid., 2, 819.

- , and - (1967). Long-term assessment of steroid treatment of idiopathic childhood nephrosis. Amer. Heart F., 74, 584.

Blodgett, F. M., Burgin, L., Iezzoni, D., Gribetz, D., and Talbot, N. D. (1956). Effects of prolonged cortisone therapy on the statural growth, skeletal maturation and metabolic status of children. New Engl. F. Med., 254, 636.

Cornfeld, D., and Schwartz, N. W. (1966). Nephrosis: a longterm study of children treated with corticosteroids. F. Pediat., $68,507$.

Etteldorf, J. N., Roy, S., III, Summitt, R. L., Sweeney, M. J., Wall, H. P., and Berton, W. M. (1967). Cyclophosphamide in the treatment of idiopathic lipoid nephrosis. ibid., 70, 758.

Falliers, C. J., Tan, L. S., Szentivanyi, J., Jorgensen, J. R., and Bukantz, S. C. (1963). Childhood asthma and steroid therapy as influences on growth. Amer.F. Dis. Child., 105, 127.

Fleisher, D. S., McCrory, W. W., and Rapoport, M. (1960). The effects of intermittent doses of adrenocortical steroids on the statural growth of nephrotic children. f. Pediat., 57, 192.

Frantz, A. G., and Rabkin, M. T. (1964). Human growth hormone. Clinical measurement, response to hypoglycemia and suppression by corticosteroids. New Engl. F. Med., 271, 1375.

Friedman, M., and Strang, L. B. (1966). Effect of long-term corticosteroids and corticotrophin on the growth of children. Lancet, 2, 568.

Good, R. A., Vernier, R. L., and Smith, R. T. (1957). Serious untoward reactions to therapy with cortisone and adrenocorticotropin in pediatric practice. (Parts I and II). Pediatrics, 19,95 and 272.

Grupe, W. E., and Heymann, W. (1966). Cytotoxic drugs in steroidresistant renal disease. Amer. F. Dis. Child., 112, 448.

Hartog, M., Gaafar, M. A., and Fraser, R. (1964). Effect of corticosteroids on serum growth hormone. Lancet, 2, 376.

Lange, K., Slobody, L., and Strang, R. (1955). Prolonged intermittent ACTH and cortisone therapy in the nephrotic syndrome: immunologic basis and results. Pediatrics, 15, 156.

Michael, A. F., Vernier, R. L., Drummond, K. N., Levitt, J. I., Herdman, R. C., Fish, A. J., and Good, R. A. (1967). Immunosuppressive therapy of chronic renal disease. New Engl. F. Med., 276, 817.

Soyka, L. F. (1967). Treatment of the nephrotic syndrome in childhood. Use of an alternate-day prednisone regimen. Amer. f. Dis. Child., 113, 693.

- and Crawford, J. D. (1964). Antagonism of human growth hormone (HGH) by cortisone. F. Pediat., 65, 1115.

, and Saxena, K. M. (1965). Alternate-day steroid therapy for nephrotic children. F. Amer. med. Ass., 192, 225.

Tanner, J. M., and Whitehouse, R. H. (1959). Standards for height and weight of British children from birth to maturity. Lancet, 2, 1086.

Ward, D. J., Hartog, M., and Ansell, B. M. (1966). Corticosteroidinduced dwarfism in Still's disease treated with human growth hormone. Clinical and metabolic effects including hydroxyproline excretion in two cases. Ann. rheum. Dis., 25, 416.

West, C. D., Hong, R., and Holland, N. H. (1966). Effect of cyclophosphamide on lipoid nephrosis in the human and on aminonucleoside nephrosis in the rat. $\mathscr{F}$. Pediat., 68, 516 .

White, R. H. R., Cameron, J. S., and Trounce, J. R. (1966). Immunosuppressive therapy in steroid resistant proliferative glomerulonephritis accompanied by the nephrotic syndrome. Brit. med. $\mathcal{F}$., 2, 853 . 